\title{
Predictors of exercise-induced bronchoconstriction in subjects with mild asthma
}

\author{
Maroon Salameh ${ }^{1,2+}$, Laura Pini ${ }^{1,2^{*}}\left(\mathbb{D}\right.$, Federico Quadri ${ }^{2}$, Fabio Spreafico ${ }^{2}$, Damiano Bottone ${ }^{2}$ and \\ Claudio Tantucci ${ }^{1,2}$
}

\begin{abstract}
Background: Physical effort is capable of triggering airway obstruction in asthmatics, the so-called exercise-induced bronchoconstriction in asthma (EIBa). This study was performed in subjects with mild persistent asthma, aiming to find predictors for developing EIBa.

Methods: In 20 subjects with mild asthma, measurements of baseline functional respiratory parameters and airways responsiveness by a methacholine challenge were obtained on the first day. A maximal, symptom-limited incremental cardiopulmonary exercise test (CPExT) was performed the day after, with subsequent, repeated maneuvers of maximal full forced expiration to monitor the FEV change at 1,3,5,7,10 and 15 min after the end of the exercise.

Results: 19 subjects completed the two-days protocol. No functional parameters both at rest and during effort were useful to predict EIBa after stopping exercise. In asthmatics with EIBa, mean Inspiratory Capacity (IC) did not increase with increasing ventilatory requirements during CPExT because 6 of them (50\%) displayed dynamic pulmonary hyperinflation $(\mathrm{DH})$, as documented by their progressive increase of end-expiratory lung volume. This subgroup, showing earlier post-exercise $F E V_{1}$ fall, had significantly lower forced mean expiratory flow between $25 \%$ and $75 \%$ of forced vital capacity $\left(\mathrm{FEF}_{25-75 \%}\right)$ at rest $(\mathrm{p}<0.05)$ and higher airways responsiveness, expressed as $\mathrm{PD}_{20} \mathrm{FEV} \mathrm{V}_{1}(\mathrm{p}<0.05)$ as compared with other asthmatics with EIBa.

Conclusions: No functional respiratory parameters seem to predict ElBa in mild asthmatics. However, in those with EIBa, a subgroup developed DH during exercise, and this was associated with a baseline reduced forced expiratory flow rates at lower lung volumes and higher airway hyperresponsiveness, suggesting a prominent small airways impairment.
\end{abstract}

Keywords: Exercise-induced asthma, Dynamic hyperinflation, Airways hyperresponsiveness, Small airway disease

\section{Background}

In patients suffering from bronchial asthma, physical exertion may acutely trigger airway obstruction leading to chest tightness, wheezing, dry cough, and dyspnea,

\footnotetext{
*Correspondence: laura.pini@unibs.it

${ }^{\dagger}$ Maroon Salameh and Laura Pini contributed equally to this study

${ }^{1}$ Respiratory Medicine Unit, Spedali Civili, Brescia, Piazzale Spedali Civili 1, Italy

Full list of author information is available at the end of the article
}

that cease spontaneously with time or more quickly after treatment, namely bronchodilators with rapid onset of action [1].

This picture is now called exercise-induced bronchoconstriction in asthma (EIBa) [2], and although sometimes may be the prominent clinical manifestation of asthma, is enough to impair lifestyle and quality of life, especially among children, teens, young adults, and original author(s) and the source, provide a link to the Creative Commons licence, and indicate if changes were made. The images or other third party material in this article are included in the article's Creative Commons licence, unless indicated otherwise in a credit line to the material. If material is not included in the article's Creative Commons licence and your intended use is not permitted by statutory regulation or exceeds the permitted use, you will need to obtain permission directly from the copyright holder. To view a copy of this licence, visit http://creativecommons.org/licenses/by/4.0/. The Creative Commons Public Domain Dedication waiver (http://creativeco mmons.org/publicdomain/zero/1.0/) applies to the data made available in this article, unless otherwise stated in a credit line to the data. 
athletes [1, 3]. A high prevalence of asthmatics can be affected by EIBa [4-6].

Usually, airflow obstruction occurs soon after the end of exercise mainly due to both osmotic and thermal mechanisms $[2,7,8]$, but sometimes may develop during exercise, limiting the subjects' physical performance [9]. In this contest, an adequate treatment of the underlying airway inflammation and, if needed, a pre-treatment with fast short-acting (rarely fast long-acting) beta- 2 selective agonists, or leukotriene-receptor antagonists is effective to control and prevent this event [10]. However, it would be useful to identify simple functional predictors of EIBa, mainly in asthmatic young people, in order to implement reliable strategies to avoid bronchoconstriction and related symptoms after or even during exercise, as much as possible. For this reason, the study aimed to identify functional parameters, either at rest or during exercise, predictors of effort-related airflow obstruction in subjects with persistent mild asthma suspected for EIBa.

\section{Methods \\ Subjects}

This prospective study was performed at the Respiratory Medicine Unit of Spedali Civili University Hospital of Brescia, Italy, from July 2018 to February 2019. To be included in the study, the subjects had to be aged 18-40 years and never smokers, have had a diagnosis of mild persistent asthma, according to GINA guidelines [11], supported by clinical judgment and objective measurements of lung function, including a positive methacholine challenge test for airway hyperresponsiveness and stable conditions for at least 8 weeks under usual treatment. Asthmatic subjects with other respiratory diseases and medical comorbidities were excluded from the study. The participants were recruited only if in the past they reported or were reported to have episodes suspected for effort-related acute respiratory symptoms.

\section{Study design \\ Functional respiratory tests}

In the morning of the first day, after an 8-hour washout from short-acting bronchodilators, 48-hour washout from long-acting bronchodilators, and 4-week washout from any inhaled corticosteroids (ICS) or oral anticysteinyl leukotrienes, each subject performed in the first-day spirometry (BIOMEDIN Instruments, Padua, Italy) wearing a nose clip and breathing through a flanged mouthpiece. Slow vital capacity (VC) and inspiratory capacity (IC) were measured twice using a bell spirometer at rest in sitting position. At least three acceptable and reproducible maximal full expiratory maneuvers were performed to measure forced vital capacity (FVC), maximal expiratory volume in the first second $\left(\mathrm{FEV}_{1}\right)$, and maximal forced expiratory flows ad different lung volumes.

Lung volumes were measured with a pressure-constant plethysmograph (BIOMEDIN Instruments, Padua, Italy). During the procedure, patients panted at a $0.7 \mathrm{Hertz}$ frequency. Three acceptable tracings of mouth pressure versus box volume changes were averaged to achieve a final measurement of functional residual capacity (FRC). Total lung capacity (TLC) and residual volume (RV) were computed subsequently. In each circumstance, the best values were collected for analysis [12]. All tests were performed according to the ERS-ATS recommendations [13]. Predicted values of lung function parameters were those proposed by the European Community for Coal and Steel [14].

In the late morning, each subject performed a challenge test for measuring nonspecific, direct airway responsiveness using doubling doses of methacholine inhaled by dosimeter (MEFAR, Brescia, Italy). The tests were stopped just after more than $20 \%$ reduction of $\mathrm{FEV}_{1}$ from baseline (saline inhalation) to calculate airway sensitivity as $\mathrm{PD}_{20} \mathrm{FEV}_{1}$.

The second day, in the late morning, each subject underwent a symptom-limited, incremental cardiopulmonary exercise test by computer-driven cyclo-ergometer with the ramping protocol (15 watts increment per $\mathrm{min}$ ) at a pedaling frequency of $50-60$ per $\min ($ CPExT). This protocol always achieved $80-90 \%$ of the predicted maximum heart rate towards the end of exercise and maintained it for few minutes. At rest and regular intervals of 2 min during exercise, the subjects were asked to inspire maximally toward total lung capacity (TLC) to obtain their inspiratory capacity (IC) that was measured off-line and expressed as \% of TLC, at $33 \%, 66 \%$ and $99 \%$ of the peak workload.

At the end of the effort, repeated full forced expiratory maneuvers were requested to obtain maximal flowvolume curves to measure $\mathrm{FEV}_{1}$ at 1-3-5-7-10-15 min after stopping exercise. $\mathrm{A} \mathrm{FEV}_{1}$ fall greater than $10 \%$ of $\mathrm{FEV}_{1}$ measured before starting exercise was considered as indicative of EIBa.

\section{Statistics}

Unless specified otherwise, data are expressed as the mean \pm standard deviation. Comparing the functional variables between groups was performed according to the Student's unpaired t-test or the Mann-Whitney U test if the normal distribution could not be assumed. Statistical significance was accepted if $p \leq 0.05$. Statistical analyses were performed using Graph Pad Prism 6.0 (Graph Pad Software, La Jolla, CA) and SPSS 23.00 (IBM, Armonk, NY). 


\section{Results}

Twenty asthmatic subjects were enrolled in the study. One subject refused CPExT and was excluded from the analysis. Among 19 subjects, 7 (37\%) did not show EIBa with a $\triangle \mathrm{FEV}_{1}$ max from baseline (made equal to 100 ) amounting to $97 \pm 6 \%$ (absolute change $-2.6 \pm 2.0 \%$ ), while 12 (63\%) had EIBa with a $\triangle \mathrm{FEV}_{1} \max$ from baseline (made equal to 100), amounting to $85 \pm 6 \%$ (absolute change $-16.2 \pm 6.7 \%$ ). Anthropometric and baseline functional data of the 19 patients of the study are shown in Table 1, all together and divided into 2 groups according to the presence or absence of EIBa. No significant differences emerged between the 2 groups. The mean duration of asthma was $11 \pm 3 \mathrm{yr}$, with no significant difference between the two groups. All subjects were treated with inhaled corticosteroids that were withdrawn 4 weeks before the study and 7 ( 2 in the group without EIBa) with long-acting beta- 2 agonists on top.

Mean data obtained at the peak of CPExT are presented in Table 2 with the IC values at different prefixed percent levels of the maximal effort, again in all subjects, and

Table 1 Anthropometric and baseline functional respiratory parameters obtained for all asthmatic subjects and those divided according to the absence (non-EIBa) or presence (EIBa) of exercise-induced bronchoconstriction

\begin{tabular}{|c|c|c|c|c|}
\hline & All & non-ElBa & ElBa & $p$ \\
\hline Subjects (n) & 19 & 7 & 12 & ns \\
\hline $\operatorname{Sex}(m-f)$ & $9-10$ & $5-2$ & $4-8$ & ns \\
\hline Age (yrs) & $27 \pm 10$ & $28 \pm 8$ & $27 \pm 11$ & ns \\
\hline Weight (kg) & $68 \pm 11$ & $72 \pm 13$ & $66 \pm 10$ & ns \\
\hline Height (m) & $1.71 \pm 0.09$ & $1.75 \pm 0.09$ & $1.69 \pm 0.09$ & ns \\
\hline $\mathrm{BMI}\left(\mathrm{kg} / \mathrm{m}^{2}\right)$ & $23 \pm 4$ & $23 \pm 2$ & $23 \pm 5$ & ns \\
\hline VC (\% pred) & $108 \pm 8$ & $107 \pm 8$ & $109 \pm 9$ & ns \\
\hline FVC (\% pred) & $109 \pm 8$ & $110 \pm 8$ & $108 \pm 9$ & ns \\
\hline IC (\% pred) & $100 \pm 15$ & $107 \pm 11$ & $96 \pm 16$ & ns \\
\hline FEV1 (\% pred) & $103 \pm 8$ & $105 \pm 11$ & $102 \pm 7$ & ns \\
\hline FEV1 NC (\% pred) & $96 \pm 7$ & $97 \pm 6$ & $95 \pm 8$ & ns \\
\hline PEF (\% pred) & $96 \pm 13$ & $101 \pm 13$ & $94 \pm 12$ & ns \\
\hline FEF $25-75 \%$ (\% pred) & $83 \pm 20$ & $88 \pm 22$ & $78 \pm 19$ & ns \\
\hline RV (\% pred) & $105 \pm 32$ & $100 \pm 22$ & $108 \pm 36$ & ns \\
\hline FRC (\% pred) & $108 \pm 31$ & $98 \pm 25$ & $113 \pm 33$ & ns \\
\hline TLC (\% pred) & $107 \pm 11$ & $104 \pm 4$ & $109 \pm 13$ & ns \\
\hline RV/TLC (\% pred) & $96 \pm 21$ & $94 \pm 21$ & $97 \pm 22$ & ns \\
\hline FRC/TLC (\% pred) & $100 \pm 21$ & $91 \pm 19$ & $105 \pm 21$ & ns \\
\hline $\mathrm{PD}_{20 \%} \mathrm{FEV}_{1}(\mathrm{mcg})$ & $123(33-683)$ & $57(40-273)$ & $170(33-683)$ & ns \\
\hline
\end{tabular}

BMI Body Mass Index, VC vital capacity, FVC forced vital capacity, IC inspiratory capacity, FEV 1 forced expiratory volume in first second, FEV1NC tiffeneau index, PEF peak expiratory flow, FEF $25-75 \%$ forced mean expiratory flow-rates between $25 \%$ and $75 \%$ of FVC, $R V$ residual volume, $F R C$ functional respiratory capacity, TLC total lung capacity, PD20\%FEV1 cumulative dose at 20\% fall of FEV1 from saline, geometric mean (range)
Table 2 Parameters obtained during CPExT at the peak of exercise and values of IC at rest (bas.) and prefixed percentages of workload during exercise for all asthmatic subjects and those divided according to the absence (non-EIBa) or presence (EIBa) of exercise-induced bronchoconstriction

\begin{tabular}{lcccc}
\hline & All & non-EIBa & EIBa & p \\
\hline Work peak (\% pred) & $104 \pm 20$ & $110 \pm 15$ & $100 \pm 22$ & ns \\
VO2 peak (\% pred) & $99 \pm 13$ & $104 \pm 15$ & $96 \pm 11$ & ns \\
HR peak (\% pred) & $91 \pm 9$ & $92 \pm 11$ & $90 \pm 8$ & ns \\
VE peak (\% pred) & $53 \pm 10$ & $53 \pm 12$ & $52 \pm 9$ & ns \\
RR peak (br/min) & $35 \pm 7$ & $33 \pm 6$ & $37 \pm 7$ & ns \\
Vt peak (L) & $1.6 \pm 0.4$ & $1.6 \pm 0.3$ & $1.6 \pm 0.5$ & ns \\
IC baseline (L) & $3.04 \pm 0.54$ & $3.19 \pm 0.66$ & $2.95 \pm 0.45$ & ns \\
IC 33\% Work peak $(L)$ & $3.03 \pm 0.56$ & $3.28 \pm 0.71$ & $2.88 \pm 0.40$ & ns \\
IC 66\% Work peak $(L)$ & $3.02 \pm 0.61$ & $3.34 \pm 0.81$ & $2.82 \pm 0.35$ & ns \\
IC 99\% Work peak $(L)$ & $3.06 \pm 0.72$ & $3.46 \pm 0.94$ & $2.81 \pm 0.44$ & ns \\
\hline
\end{tabular}

VO2 oxygen consumption, $H R$ heart rate, $V E$ minute ventilation, $R R$ respiratory rate, $V t$ tidal volume, $I C$ inspiratory capacity

Data are mean \pm SD

divided into 2 groups: those without EIBa, and those with EIBa. Not significantly different values of main variables of interest at peak exercise were found between the 2 groups. However, while mean IC progressively increased throughout exercise in asthmatics without EIBa, mean IC slightly decreased during exercise in asthmatics with EIBa.

The end-inspiratory (EILV as \%TLC) and endexpiratory (EELV as \% TLC) lung volume changes during exercise are illustrated in Fig. 1, panel $\mathrm{a}$ and $\mathrm{b}$ for the non-EIBa and EIBa groups, respectively, indicating a possible exertional dynamic pulmonary hyperinflation (DH) in asthmatics with EIBa. However, looking at the individual measurements of IC during exercise in asthmatics with EIBa, 6 out of $12(50 \%)$ displayed a progressive, significant IC decrease and EELV (as \%TLC) increase (EIBa subgroup 2), reflecting a noticeable DH. In contrast, the other 6 (EIBa subgroup 1) had normal lung mechanics behaviour during the effort, similar to that shown by the asthmatics without EIBa (see Table 3 and Fig. 1, panel d and c). The other different variable at the peak of exercise between the two subgroups with EIBa was the respiratory rate, much higher in the EIBa subgroup $2(41.3 \pm 6.5$ vs $33.3 \pm 6.4, \mathrm{p}<0.05)$.

By comparing the lung function measurements at rest between these two subgroups of asthmatics with EIBa, the only different parameter resulted in the maximal mean expiratory flow rate between $25 \%$ and $75 \%$ of forced vital capacity $\left(\mathrm{FEF}_{25-75 \%}\right)$, which was significantly reduced in the subgroup with DH (EIA subgroup 2) $(64 \pm 16 \%$ pred. vs $91 \pm 10 \%$ pred., respectively; $\mathrm{p}<0.05)$, suggesting a greater structural involvement 

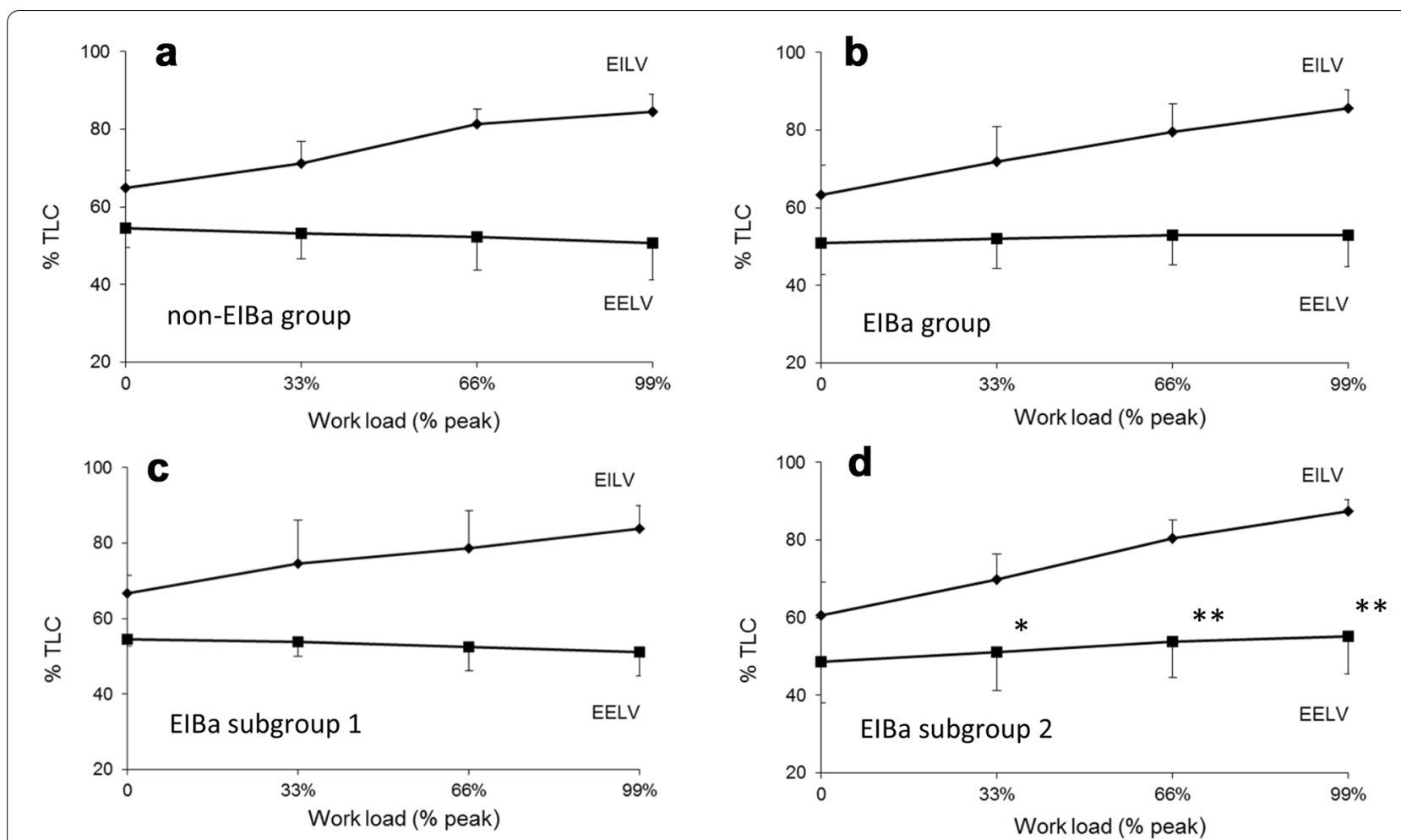

Fig. 1 End-expiratory (EILV as \% TLC; squares) and end-inspiratory (EELV as \% TLC; diamonds) lung volume changes during exercise in asthmatics without EIBa $(n=7 ; \mathbf{a})$ and in asthmatics with EIBa $(n=12 ; \mathbf{b})$. EILV (squares) and EELV (diamonds) changes during exercise in asthmatics with EIBa without $(n=6 ; \mathbf{c})$ and with $(n=6 ; \mathbf{d})$ dynamic pulmonary hyperinflation. ${ }^{*} p<0.05,{ }^{* *} p<0.01$ vs rest

Table 3 Values of IC at rest (baseline) and prefixed percentages of workload during CPEXT in asthmatic subjects with EIBa, divided according to the absence (subgroup 1) or presence (subgroup 2) of exercise-induced pulmonary dynamic hyperinflation

\begin{tabular}{lll}
\hline & EIBa (subgroup 1) & EIBa (subgroup 2) \\
\hline IC baseline. (L) & $2.78 \pm 0.44$ & $3.09 \pm 0.45$ \\
IC 33\% Work peak (L) & $2.81 \pm 0.42$ & $2.93 \pm 0.41^{*}$ \\
IC 66\% Work peak (L) & $2.87 \pm 0.27$ & $2.78 \pm 0.43^{* *}$ \\
IC 99\% Work peak (L) & $2.95 \pm 0.29$ & $2.70 \pm 0.53^{* *}$ \\
\hline
\end{tabular}

IC inspiratory capacity

Data are mean $\pm S D$

${ }^{*} p<0.05$ and ${ }^{* *} p<0.01$ vs baseline

(inflammation/remodelling) of the small airways in these subjects (Fig. 2a). Patients with EIBa subgroup 2 showed significantly lower FEF25-75\% values than patients without EIBa (64 $\pm 16 \%$ pred. vs $88 \pm 22 \%$ pred., respectively; $\mathrm{p}<0.05$ ).

Interestingly, $\mathrm{PD}_{20} \mathrm{FEV}_{1}$ was markedly lower in the subgroup with EIBa and with $\mathrm{DH}$ (geometric mean 55 (33-261) mcg vs 389 (101-683) mcg; p < 0.05), partly explained by larger ventilation heterogeneity that is a marker of peripheral airway impairment (Fig. 2b). The $\mathrm{PD}_{20} \mathrm{FEV}_{1}$ value of the group without EIA was not different from the $\mathrm{PD}_{20} \mathrm{FEV}_{1}$ value observed in EIBa subgroup 2, amounting to 57 (40-273) mcg vs 55 (33-261) mcg, respectively. No differences were found between the non-EIBa group and EIBa subgroup 1 concerning baseline pulmonary function tests (including $\mathrm{FEF}_{25-75 \%}$ ) and parameters obtained during CPExT.

Finally, the post-exercise fall in $\mathrm{FEV}_{1}$, albeit more rapid and pronounced in the EIBa patients with $\mathrm{DH}$ during exercise (EIBa subgroup 2) as compared with those with EIBa without DH during exercise (EIBa subgroup 1), was not significantly different between them (Fig. 3).

\section{Discussion}

The main findings of the study are the following. No functional parameter either at rest or during exercise was significantly different and able to distinguish in a population of subjects with mild persistent asthma who would have had EIBa and who not. In contrast with asthmatics without EIBa, IC did not increase during exercise in those with $\mathrm{EIBa}$, and some of them (in our series 50\%) developed DH during exercise with earlier 


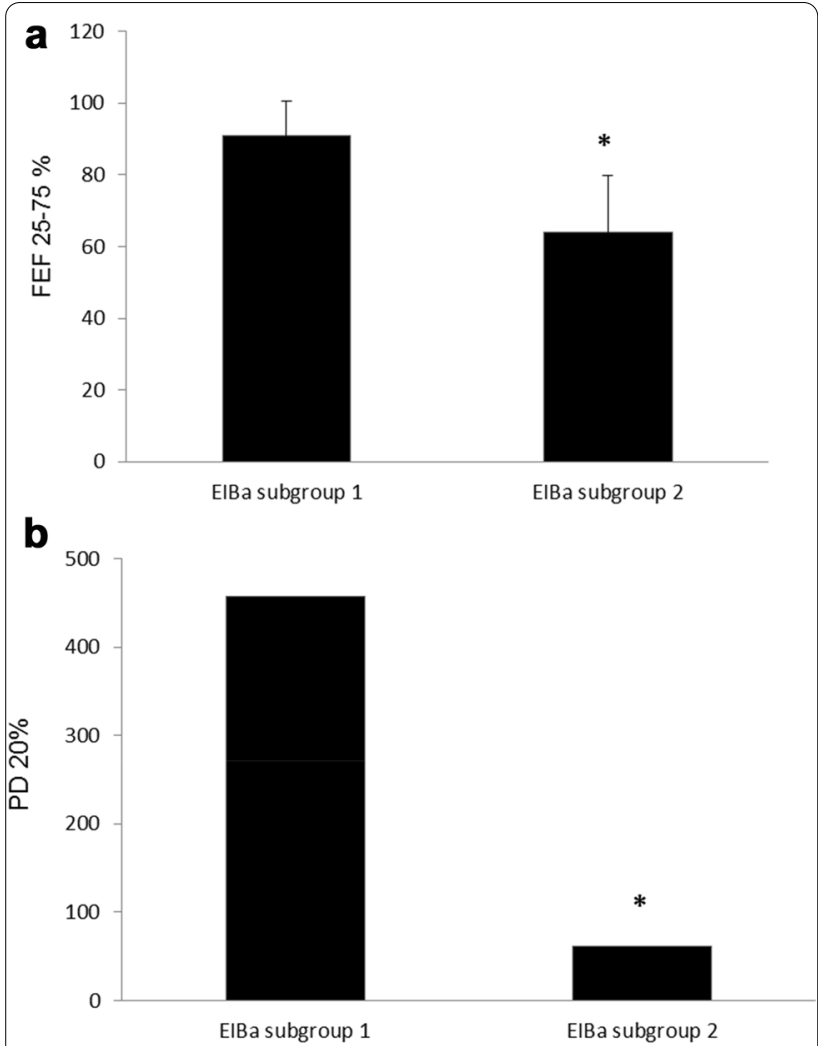

Fig. 2 Mean Forced expiratory flow rates between 25 and $75 \%$ of $\mathrm{FVC}\left(\mathrm{FEF}_{25-75 \%}\right)$ at rest in asthmatics with ElBa, without (subgroup 1), and with (subgroup 2) dynamic pulmonary hyperinflation during exertion (panel a) ${ }^{*} p<0.05$. The provocative dose of methacholine causing a 20\% FEV 1 fall from baseline (saline) $\mathrm{FEV}_{1}\left(\mathrm{PD}_{20} \mathrm{FEV}_{1}\right)$ in asthmatics with ElBa, without (subgroup 1), and with (subgroup 2) dynamic pulmonary hyperinflation during exertion (panel b) * $p<0.05$. Geometric mean

$\mathrm{FEV}_{1}$ fall after stopping it. This subgroup of asthmatics with EIBa with DH during exercise (subgroup 2) showed a significant reduction of $\mathrm{FEF}_{25-75 \%}$ at rest and higher airway responsiveness to methacholine, suggesting a more extensive structural and functional involvement of small airways.

We did not find any respiratory functional parameters at rest, useful to predict the occurrence of exerciseinduced bronchoconstriction in relatively young asthmatics with similar history and severity of disease (mild persistent asthma). Also, although patients developing EIBa had slightly lower mean peak values of workload and oxygen uptake during exercise, there were no significant differences in average between the two groups.

However, asthmatics with EIBa did not exhibit the expected EELV reduction during exercise (Fig. 1) with a number of them who developed $\mathrm{DH}$, as witnessed by the progressive IC decrease and excessive RR increase at peak exercise (EIBa subgroup 2). These exertional mechanical constraints were associated with significantly reduced forced expiratory flows at lower lung volumes at baseline and higher airway responsiveness. In the presence of normal $\mathrm{FEV}_{1}$ and FVC, reduced $\mathrm{FEF}_{25-75 \%}$ strongly suggest an increased upstream resistance in these asthmatics' small airways that, favouring a larger ventilation heterogeneity, may in part explain the higher airway hyperresponsiveness we observed concurrently [15].

The baseline reduced expiratory flow reserve at lower lung volumes, corresponding to the tidal volume range, may promote tidal expiratory flow limitation (EFL) when the ventilatory requirements increase during exertion. This possibility that is the occurrence of EFL was elegantly demonstrated by Kosmas and coworkers some years ago, using the negative expiratory pressure technique, in a large percentage of subjects suffering from asthma of different severity, from intermittent or mild to severe, but without EIBa, during symptomlimited incremental bicycle exercise test [16]. Interestingly, asthmatics who developed EFL during exercise had a lower baseline $\mathrm{FEF}_{25-75 \%}$ and $\mathrm{FEF}_{75 \%}$ than those without EFL. An increment of airway resistance throughout the exercise observed in some asthmatics $[16,17]$, especially with EIBa $[9,18,19]$, can markedly increase this possibility. In these circumstances breathing at higher operative lung volumes allows to escape tidal EFL or have minimal EFL and continue exercising but at the expense of progressive DH [20].

Therefore, these indices such as $\mathrm{FEF}_{25-75 \%}$ and $\mathrm{PD}_{20} \mathrm{FEV}_{1}$, easily obtained at rest, could explain why some asthmatics with EIBa may have symptoms also during effort linked to the development of $\mathrm{DH}$ that might limit their exercise tolerance and maximal performance because of its associated mechanical constraints.

In the future would be interesting by using FOT to measure parameters of respiratory system resistance (Rrs5-Rrs20 difference) and reactance (Xrs5 or AX), exploring small and peripheral airway mechanical properties, to confirm this hypothesis in asthmatics suffering from EIBa who begin to have mechanical lung impairment and related symptoms also during effort [21]. Higher airway hyperresponsiveness (i.e., higher sensitivity as $\mathrm{PD}_{20} \mathrm{FEV}_{1}$ ) can ensue from deeper epithelial damage associated with either greater airway inflammation or abnormal neurogenic control or both, and this condition may certainly induce a worse functional impairment of small airways. Concurrently, larger ventilation heterogeneity sustained by a marked small airway involvement might also explain higher airway hyperresponsiveness [14]. We cannot discriminate 

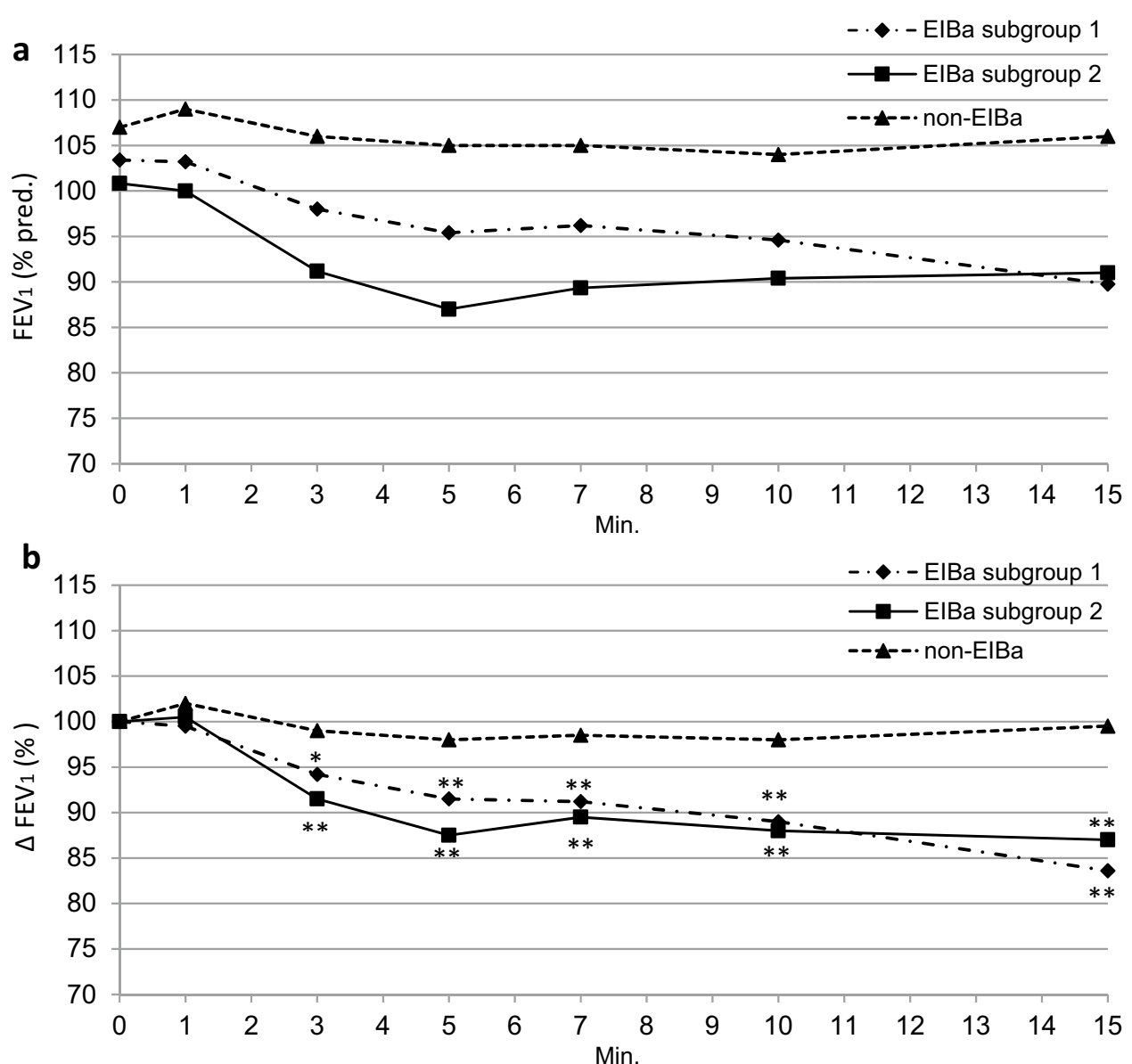

Fig. 3 Changes of $\mathrm{FEV}_{1}$ both as absolute values (\% pred.) (a) and as \% change from baseline $\left(\Delta \mathrm{FEV}_{1} \%\right)(\mathbf{b})$ after stopping exercise in asthmatics without EIA $(n=7)$ and with EIBa, without $(n=6$; subgroup 1$)$ and with $(n=6$; subgroup 2$)$ dynamic pulmonary hyperinflation during exertion $(\mathrm{DH})$

between these two different mechanisms that, however, could coexist in this subgroup of asthmatics with EIBa.

This study is limited by the relatively small number of subjects and possibly by choice of the exercise challenge that is less than optimal for induction of EIBa, but needful to measure the operational lung volumes dynamic changes. However, we were able to elicit EIBa in more than $60 \%$ of the subjects recruited for suspicious exertional symptoms. Finally, we do not think that the absence of a matched control group could invalidate our findings' meaning.

\section{Conclusions}

None of the routine functional parameters measured at rest and during exercise can distinguish among mild asthmatics those who will develop EIBa or not. However, in some mild asthmatics with EIBa, dynamic hyperinflation can occur during exercise, possibly limiting their exercise tolerance and performance. Such as unfavourable mechanical constraint is associate with significantly decreased forced mean flow rates at lower lung volumes at rest and higher airway hyper-responsiveness, suggesting a more profound involvement of small airways in these subjects. That may explain why some asthmatics with EIBa become symptomatic during effort and not only after stopping it.

\section{Abbreviations}

EIBa: Exercise-induced bronchoconstriction in asthma; ICS: Inhaled corticosteroids; VC: Vital capacity; IC: Inspiratory capacity; FVC: Forced vital capacity; FEV1: Maximal expiratory volume in the first second; FRC: Functional residual capacity; TLC: Total lung capacity; RV: Residual volume; CPEXT: Cardiopulmonary exercise test; EILV: End-inspiratory lung volume; EELV: Endexpiratory lung volume; DH: Dynamic hyperinflation; FEF25-75\%: Expiratory flow-rate between $25 \%$ and $75 \%$ of forced vital capacity.

\section{Acknowledgements}

The Authors acknowledge Mr. M. Guerini, Lab. technician, for his invaluable technical support. 


\section{Authors' contributions}

CT and MS: study design. MS, FS, FQ, and LP: data collection. LP, DB, and FS: data analysis. All authors: interpretation of results. CT: initial draft. All authors: review of the manuscript for intellectual content. All authors have read and approved the final manuscript

\section{Funding}

Not applicable.

\section{Availability of data and materials}

All data generated or analyzed during this study are included in this published article.

\section{Declarations}

\section{Ethics approval and consent to participate}

The study was performed in accordance with the Helsinki declaration and was approved by the local University Hospital Ethic Committee.

\section{Consent for publication}

All the study's participants signed a Written Informed Consent

\section{Competing interests}

$M S, L P, F Q, F S, D B$ and $C T$ reports no conflicts of interest in this work:

\section{Author details}

${ }^{1}$ Respiratory Medicine Unit, Spedali Civili, Brescia, Piazzale Spedali Civili 1, Italy. ${ }^{2}$ Department of Clinical and Experimental Sciences, University of Brescia, Brescia, Italy.

Received: 15 March 2021 Accepted: 3 August 2021

Published online: 14 August 2021

\section{References}

1. Weiler JM, Anderson SD, Randolph C, et al. Pathogenesis, prevalence, diagnosis and management of exercise-induced bronchoconstriction: a practice parameter. Ann Allergy Asthma Immunol. 2010;105(suppl):S1-47.

2. Couto M, Kurowski M, Moreira A, et al. Mechanism of exercise-induced bronchoconstriction in athletes: current prospective and future challenges. Allergy. 2018;73:8-16.

3. Randolph CC, Dreyfus D, Rundell KW, Bangladore D, Fraser B. Prevalence of allergy and asthma symptoms in recreational roadrunners. Med Sci Sports Exerc. 2006;38:2053-7.

4. Cabral AL, Conceiçao GM, Fonseca-Guedes CH, Martins MA. Exerciseinduced bronchospasm in children: effects of asthma severity. Am J Respir Crit Care Med. 1999;159:1819-23.
5. Weiler JM, Bonini S, Coifman R, et al. American Academy of Allergy, Asthma and Immunology work group report: exercise-induced asthma. J Allergy Clin Immunol. 2007;119:1349-58.

6. Boulet L-P, O'Byrne P. Asthma and exercise-induced bronchoconstriction in athletes. New Engl J Med. 2015:372:641-8.

7. Anderson SD, Kippelen P. Exercise-induced bronchoconstriction: pathogenesis. Curr Allergy Asthma Rep. 2005:5:116-22.

8. McFadden ER Jr. Exercise-induced airway obstruction. Clin Chest Med. 1995:16(4):671-82.

9. Suman OE, Babock MA, Pegelow DF, et al. Airway obstruction during exercise in asthma. Am J Respir Crit Care Med. 1995;152:24-31.

10. Smoliga JM, Weiss P, Rundell KW. Exercise-induced bronchoconstriction in adults: evidence based diagnosis and management. BMJ. 2016;352:1-8.

11. Global Initiative for Asthma. Global Strategy for Asthma Management and Prevention; 2019.

12. Tantucci C, Bottone D, Borghesi A, Guerini M, Quadri F, Pini L. Methods for measuring lung volumes: is there a better one? Respiration. 2016;91(4):273-80.

13. Miller MR, Crapo R, Hankinson J, et al. General considerations for lung function testing. Eur Respir J. 2005;26:153-1611.

14. Quanjer PH, Tammeling GJ, Cotes JE, Pedersen OF, Peslin R, Yernault JC. Lung volumes and forced ventilatory flows. Eur Respir J. 1993;6(Suppl 16):5-40.

15. Downie SR, Salome CM, Verbanck S, et al. Ventilation heterogeneity is a major determinant of the airway responsiveness in asthma, independent of airway inflammation. Thorax. 2007;62:684-9.

16. Kosmas EN, Milic-Emii J, Polychronaki A, et al. Exercise-induced flow limitation, dynamic hyperinflation and exercise capacity in patients with bronchial asthma. Eur Respir J. 2004;24:378-84.

17. Beck KC, Offord KP, Scanlon PD. Bronchoconstriction occurring during exercise in asthmatic subjects. Am J Respir Crit Care Med. 1994;149:352-7.

18. Jonhson BD, Scanlon PD, Beck KC. Regulation of ventilatory capacity during exercise in asthmatics. J Appl Physiol. 1995;79:892-901.

19. Cypcar D, Lemanske RF Jr. Asthma and exercise. Clin Chest Med. 1994;15(2):351-68.

20. Tantucci C, Ellaffi M, Duguet A, et al. Dynamic hyperinflation and flow limitation during methacholine-induced bronchoconstriction in asthma. Eur Respir J. 1999;14:295-301.

21. Oosteveen $\mathrm{E}, \mathrm{MacLeod} \mathrm{D}$, Lorino $\mathrm{H}$, et al. The forced oscillation technique in clinical practice: methodology, recommendations, and future development. Eur Respir J. 2003;22:1026-41.

\section{Publisher's Note}

Springer Nature remains neutral with regard to jurisdictional claims in published maps and institutional affiliations.
Ready to submit your research? Choose BMC and benefit from:

- fast, convenient online submission

- thorough peer review by experienced researchers in your field

- rapid publication on acceptance

- support for research data, including large and complex data types

- gold Open Access which fosters wider collaboration and increased citations

- maximum visibility for your research: over 100M website views per year

At BMC, research is always in progress.

Learn more biomedcentral.com/submissions 